\title{
Faculty Presence Promotes Quality Of Education In The Online Asynchronous Classroom
}

\author{
Kimberly O'Reilly, Still University, USA
}

\begin{abstract}
As online education continues to thrive, as indicated by increased acceptance and growing enrollment numbers, schools must strive to provide high quality educational opportunities to their students. Interaction within the classroom is one method of instruction that has been accepted in traditional settings and should be utilized within online classrooms as well. A review of the literature that addresses how interaction creates presence within the online environment will help to establish how interaction creates presence and will describe what tools faculty should utilize and the types of presence for which faculty should strive and why.
\end{abstract}

Keywords: Faculty, Instructor, online, interaction, presence, asynchronous interaction, faculty presence, social presence, online learning, faculty satisfaction, pedagogical presence, managerial presence

\section{INTRODUCTION}

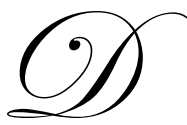

istance education is not, as some assume, a new practice. Distance education has been around for over 150 years. In the beginning, the overarching goal of distance education was to bring educational opportunities to people who were unable to access traditional education through correspondence courses. Through the years, the delivery methodology has grown from correspondence to radio, television and now internet services. Online education is a type of distance education; it is not the definition of distance education (Emmerson, 2005). Today, there are more than two million online students (Allen, 2006).

Students are clamoring for instructor presence and practical application within the online environment. Quotes from real students reveal the importance of faculty presence and increased interaction within the online classroom.

- $\quad$ "First off, the instructor participation is non-existent. When he does respond to questions, the responses are one-word answers that don't make any sense" (Public Health Education Concepts course evaluation by a student Fall 2006 quarter).

- "More faculty interaction in the discussion" (Epidemiology course evaluation by a student Fall 2006 quarter).

- "More real life situations" (Environmental Health Science course evaluation by a student Fall 2006 quarter). Without instructor presence and quality interaction, online classrooms will lose students.

- $\quad$ "The discussions. No one reads my discussions, and they rarely respond to my response to their work. I miss real class interactions" (Epidemiology course evaluation by a student Fall 2006 quarter). In order to provide online students with the best possible education, we must listen to their needs and find ways to create optimum interaction within the online discussion forum. Online asynchronous discussion forums are "the primary way of building interactivity into course" (Collins-Brown, 2001).

As online education continues to expand, universities need to pay particular attention to the quality of education they are providing. One way to increase this quality is to focus on the number of interactions that occur within an online classroom. Online interaction points are most productive when material is presented and processed 
in a practical manner. The practical manner of application provides an opportunity for increased communication between students and faculty. This increased communication also provides for a more student-centered environment. When faculty assists with making connections between multiple student ideas and provides further facilitation on ideas and issues, the knowledge growth is endless. This frequent and fruitful communication removes some of the feelings of disconnect online students discuss; interaction is presence!

\section{INTERACTION POINTS}

There are several faculty interaction points that are important in the creation of an optimum online learning environment. It is important for online faculty to use all interaction points on a weekly basis as they assist in forming bonds, create an instructor presence, enhance opportunities for increased interaction and help establish and maintain a student centered learning community (Collins-Brown, 2001). Many faculty members are evaluated based on the expectation that they take every opportunity possible to interact with their students. Based on a review of five course management systems (Questa, Moodle ${ }^{\circledR}$, E-College ${ }^{\circledR}$, WebCT ${ }^{\circledR}$ and Blackboard $®$ ), the following interaction points are important to the online learning environment:

- $\quad$ Announcements - one way communication between faculty and students (Collins-Brown, 2001).

- $\quad$ E-mail - one or two way asynchronous communication between faculty and students; students and students (Garrison, 2000).

- $\quad$ Discussion Forums - one or two way asynchronous communication between faculty and students; students and students (Gilbert \& Dabbagh, n.d.).

- $\quad$ Feedback summaries - one or two way asynchronous communication between faculty and students; students and students (Collins-Brown, 2001).

- $\quad$ Chat sessions - two way synchronous communication between faculty and students; students and students (Garrison, 2000).

Faculty can interact with students by sending weekly announcements. These announcements serve as starting and ending points for each week, similar to how a faculty member might start and end a traditional class session. Announcements provide overviews and summaries of topics and help identify gaps between student perceptions of what a particular assignment requires and what an instructor requires. Announcements can be customized to each classroom based on performance of the students and their interaction levels. Faculty can use this form of communication to identify classroom strengths and weaknesses. Further, announcements can encourage additional reading, provide increased feedback and rearrange teaching styles and expectations if it will better serve the learning environment (Collins-Brown, 2001).

Individual e-mail is another important interaction point within the online classroom. Individual e-mail provides an instructor the opportunity to connect with students in a more detailed manner. In this nonpublic forum, an instructor can be more specific about areas of weakness and provide detailed feedback, support, and assistance. The thought is a student is more likely to accept assistance and support when not being singled out within the discussion forum environment. Individualized e-mail is also another conversation point. Students may feel more connected if they are contacted individually as well as within the classroom as a whole (Garrison, 2000).

Feedback given within the discussion forum or via the email system can be formative or summative in nature. Formative feedback is generally given prior to a grade being assigned. The purpose of formative feedback is to assist students in understanding the material being presented and assignment expectations. Formative feedback gives a student an opportunity to better understand an assignment prior to earning a grade. Upon grading an assignment, an instructor can provide summative feedback. Summative feedback helps students understand why they earned a particular grade, while explaining why points were deducted. This feedback can be beneficial to the students on future assignments (Garrison \& Ehinghaus, 2007). Feedback should be viewed as a teachable moment and therefore, should be about learning rather than finding fault. This essential touch point should be seen as an opportunity for growth and understanding within the subject matter rather than growth and understanding of the grading process (Collins-Brown, 2001). 
Synchronous chat features allow students and instructors to participate in real time conversation. Chat features use synchronous technology to allow for text based discussions. Synchronous communication may or may not be required in an online learning environment (Garrison, 2000). Synchronous chat features may be a part of the physical online classroom or may be supplemental technology such as Yahoo, Oovoo, MSN Messenger, etc.

The asynchronous discussion forum, as its name implies, is a place to discuss material related to the desired outcomes and objectives of a course. Asynchronous discussion forums provide an initial topic and then seek to engage students and faculty in a multi-level conversation about that and other related topics. The nature of asynchronous discussions encourages reflection and peer to peer learning as well as instructor to student learning. The posts are available through the course for reference and a multitude of experiences among students provides for increased understanding of material (Collins-Brown, 2001). Morris, Haizia \& Finnegan (2005) suggest the discussion forum is a key to increasing interaction. Many instructors are unsure how to utilize this very important tool. It is proposed that if the discussion forum is not utilized properly, the integrity and effectiveness of online learning is compromised.

Faculty members are in a unique position and have inimitable opportunities to strengthen a student personally and professionally. Understanding what skills and characteristics encourage and strengthen the power of knowledge is essential in today's educational environment. Training and standard operating procedures are a must in order to facilitate the best possible online course. According to Gilbert \& Dabbagh (n.d.), research is lacking in the area of protocols that will promote online learning within the asynchronous discussion forum; therefore, "a major challenge facing the instructor in distance learning settings is how to structure online discussions in order to engage students in meaningful discourse" (Gilbert \& Dabbah, n.d.). By increasing interaction and utilizing specific skills and characteristics, instructors can provide the increased quality online education will come to expect.

\section{FACULTY PRESENCE}

Just as faculty members have expectations of students, students have expectations of faculty. It is vitally important that faculty understand what student expectations are and how to meet them. Swan \& Shih (2005) discuss some of the faculty characteristics necessary for student satisfaction in an online classroom. These include the student perception of:

$$
\begin{array}{ll}
- & \text { Interaction } \\
\text { - } & \text { Faculty presence } \\
\text { - } & \text { Social presence } \\
\text { - } & \text { Faculty satisfaction } \\
\hline & \text { Learning }
\end{array}
$$

All five of these should be found in and used effectively within the discussion forum.

Interaction is the process of online faculty working with students individually and in groups in an effort to discuss materials (Gilbert \& Dabbagh, n.d.). This interaction may include the following:

- $\quad$ Application of material to proposed career

- $\quad$ Application of material to current positions

- Application of material to previous learned information

- Questions or concerns a student may have

Interaction is also used in providing feedback on work in progress (formative) and work submitted for a grade (summative).

Faculty presence is the feeling of students that they are being taught by an individual, particularly within the discussion forum. The faculty is present when they are seen as more than just a name on a page or a person 
assigning a grade. Faculty presence is part of demonstrating personality, knowledge, and understanding (Wood, n.d.).

Social presence is the idea that students wish to have non-academic related conversations and accolades to break up the pressures of the course material. Ending e-mails, posts and feedback with compliments, recognition of personal information shared (example - "I hope your daughter is feeling better") and other simple statements and questions demonstrate this attribute (Garrison, 2000).

Faculty satisfaction is the perception that the faculty is enjoying her/his position. Demonstration of passion for education and the subject matter helps to display satisfaction. Other characteristics that demonstrate faculty satisfaction include caring about students and caring about students meeting course outcomes. An overall sense of a personality behind the typing leads to increased interactions (Beuchot \& Bullen, 2005).

Interaction can be defined as enhancing the understanding and applicability of particular material or on a given topic (Collins-Brown, 2001). Discussion forums provide access to faculty to demonstrate all five points outlined by Swan \& Shih (2005). Review of the literature suggests most studies agree that faculty presence is the primary ingredient to student satisfaction and increased interaction. Based on several articles, perception of presence is an acceptable form of actual presence.

The perception of presence is the most influential attribute in determining satisfaction and success in online courses (Swan \& Shih, 2005). Hiltz (2005) reports, “...[Of the]many variables that contribute to and help to explain the effectiveness of courses taught using the Asynchronous Learning Network (ALN) paradigm, the most important is the pedagogy and the presence that the faculty brings to the course." According to Morris et al., (2005), there are three types of faculty presence, two of which are directly related to the discussion forum.

- $\quad$ Pedagogical presence of the faculty

- $\quad$ Social presence of the faculty

- Managerial presence of the faculty

Pedagogical presence of the faculty relates to subject matter. Students take the primary responsibility for learning within the discussion forum and the faculty facilitates this process. Within a discussion forum, all students provide an answer to the same question. The faculty then posts various comments and questions to each student individually. Questions are meant to diversify the discussion and expand the topic and application. Students are expected to post to the comments of their faculty and peers. The faculty continues to facilitate this conversation and provide guidance, feedback and summarizes the material presented.

Social presence refers to subject matter not directly related to the course. Social presence includes discussion forum postings that delve into real life situations and encourage the students to apply material to them and think outside of the box. Social presence increases the awareness of the realness of a faculty.

Pedagogical presence and social presence relate to interacting with the student and enhancing the understanding of presented materials within the discussion forum. Students also may need assistance with their technology and other outside environmental issues that might interfere with their ability to learn. These environmental issues lead us to the managerial presence of the faculty.

The managerial role is focused on things related to the course but not related to the curriculum (Morris et al., 2005). Students and faculty need to understand and appreciate the emotional expectations and wellness issues related to increasing online interaction. Faculty can better work with students if they have a strong understanding of the following management skills (J. Persavich Ph.D., personal interview, October 3, 2006):

- $\quad$ Time management - the ability of a student and faculty to fit schoolwork and classroom time into their daily routine.

- $\quad$ Social management - the ability of a student and faculty to fit social time into their daily routine without interfering with their school time. 
- $\quad$ Family management - the ability of student and a faculty to fit family commitments and quality family time into their daily routine without interfering with their school time.

- Work management - the ability of a student and a faculty to fit work commitments into their daily routine without interfering with their school time.

Each of the interaction points fit into one of the three modalities of presence. By guiding and facilitating students through interaction that promotes critical thinking and practical application, faculty are increasing the likelihood of knowledge transfer in the online environment.

\section{CONCLUSION}

Hiltz (2005) reports collaboration within the online classroom increases faculty presence and student success. Jing \&Ting (1999) hold that students believe increased interaction within the classroom improves the quality of learning that takes place. It is conceivable, then, that if a faculty engages students in the online asynchronous environment using multiple interaction points, the students will participate at a higher level. This increased interaction within the online asynchronous classroom will increase the perception of the quality of learning.

\section{AUTHOR INFORMATION}

Kimberly O'Reilly, D.H.Ed., M.S.W., holds a doctorate of health education and a master of social work, with a bachelor's degree in psychology and a history minor. Dr. O'Reilly is an alumnus of Purdue University, Indiana University and A.T. Still University. She practiced in the field of mental health for five years prior to entering the higher education field. Since 2004, she has worked in online education teaching, creating assessment plans, developing and designing curriculum, developing programs and individualized education plans, and providing both faculty and student support services. Dr. O'Reilly's areas of interest included improving the quality of higher education, educational technologies, bridging the gap between traditional and non-traditional educational practices, decreasing parental rights termination through proactive interventions and improving quality of life for the terminally ill and aging populations.

\section{REFERENCES}

1. Allen, I. Elaine \& Seaman, Jeff (2006) Making the Grade: Online Education in the United States, 2006. Retrieved on December 13, 2006 from http://www.sloanc.org/publications/survey/pdf/making_the_grade.pdf

2. Beuchot, Alberto \& Bullen, Mark (2005). Interaction and Interpersonality in Online Discussion Forums. Distance Education, 26(1) p. 67-87.

3. Collins-Brown, Eli (2001). Successful Strategies for Using Asynchronous Discussion in College Courses. Treatise Presentation Texas Christian University Education Research/Educational Technology. April 17, 2001.

4. Emmerson, Anne (2005) The History of the Changes in Practices of Distance Education in the United States from 1852 - 2003. Dissertations \& Theses, Proquest Psychology Journals (AAT 3157941).

5. Garrison, D.R. (2000). Theoretical Challenges for Distance Education in the Twenty-First Century: A shift From Structural to Translational Issues. International Review of Research and Open and distance Learning, 1(1). Retrieved on November 12, 2007 from http://www.icap.org/iuicode?149.1.1.2

6. Gilbert, Patricia K. \& Dabbagh, Nada (n.d.) How to Structure Online Discussions for Meaningful Discourse. Retrieved on November 11, 2007 from http://www.aect.org/divisions/gilbert.asp

7. Jiang, M. and Ting, E. (1999). A Study of Student' Perceived Learning in a Web-Based Online Environment. Paper presented at the World Conference of WWW and the Internet, Honolulu, HI.

8. Morris, Libby V., Xiau, Haixia, \& Finnegan, Catherine L. (2005). Roles of Faculty in Teaching Asynchronous Undergraduate Courses. Journal of Asynchronous Learning Networks, 9(1), 65-82.

9. Swan, Karen, \& Shih, Li Fang (2005). On the Nature and Development of Social Presence in Online Course Discussions. Journal of Asynchronous Learning Networks, 9(3), 115-134. 
10. Wood, Elliot (n.d.) A Dilemma Beyond Discussion - Increasing Student Interaction in External Study Modes. Retrieved on November 11, 2007 from

http://www.ecu.edu.au/conferences/tlf/2002/pub/docs/Wood.pdf

\section{NOTES}

